\title{
Measurement of reduction in packed bed of iron ore and carbon under one-dimensional heating
}

\author{
T. Coetsee ${ }^{1}$ and P. C. Pistorius ${ }^{* 2}$
}

\begin{abstract}
An experimental configuration was developed to quantify the rate of heat transfer into an iron orecarbon mixture during one-dimensional radiative heating. Repeatability and accuracy were evaluated by comparing the results of a radiation network calculation with a mass and energy balance, and by comparing predicted carbon contents after reaction with analysed carbon contents. For a sample consisting of prereduced ore and graphite, heat transfer is limited by both radiation to the sample surface and conduction into the sample; the off-gas analysis indicates that both the gaseous reduction reaction and carbon gasification are significantly away from equilibrium. The configuration is shown to yield reliable results for this complex combination of reaction steps.
\end{abstract}

Keywords: Carbothermic reduction, Heat transfer control, Direct reduction

\section{Introduction}

Carbothermic reduction is inherently endothermic, and hence requires the transfer of heat to the reaction sites. This paper focuses on construction and testing of an experimental configuration which allows quantification of heat transfer to and reduction within a packed bed containing iron ore and coal. Quantification of heat transfer is important for an understanding of reduction kinetics because in many cases the rate of heat transfer is rate controlling, or codetermines (with the chemical kinetics) the overall rate of reduction. ${ }^{1}$ As was pointed out before, neglect of a limiting role of heat transfer can lead to incorrect analysis of the underlying reaction kinetics. $^{2}$

A significantly limiting effect of heat transfer can be recognised by a significant difference in temperature between the source of heat and the reaction sites. Examples include: coal based direct reduction of iron ore in a rotary kiln, where the temperature of the solids bed is substantially lower than the gas freeboard and kiln wall, ${ }^{3}$ and where more reactive coal causes a decrease in the temperature of the solids bed; ${ }^{4}$ and reduction in agglomerated composites of iron ore and coal, where heat conduction into the composite is rate determining in larger composites. ${ }^{5-7}$

Industrial processes where coal is used as reductant for iron oxide, and where heat transfer plays an important and possible limiting role, include FASTMET/FASTMELT ${ }^{8}$ SL/RN kiln based direct

\footnotetext{
${ }^{1}$ Exxaro Resources, PO Box 9229, Pretoria 0001, South Africa

${ }^{2}$ Department of Materials Science and Engineering, Carnegie Mellon University, Pittsburgh, PA 15213, USA

(Both authors were in the Department of Materials Science and Metallurgical Engineering, University of Pretoria at the time the work was carried out.)

*Corresponding author, email pistorius@cmu.edu
}

reduction, ${ }^{9}$ and the proposed paired straight hearth ${ }^{10}$ and Ifcon ${ }^{11-13}$ processes. The experimental configuration which was developed in the work reported here is most relevant to the Ifcon process, in which a mixture of ore fines, coal and fluxes of $-10 \mathrm{~mm}$ is fed onto a liquid metal bath to form heaps floating on the metal bath; the freeboard is heated by combustion of natural gas and of the gases (containing coal volatiles, hydrogen and carbon monoxide) emitted from the heaps; the metal bath below is heated by inductors.

This paper details the construction and calibration of the experimental setup; the larger study ${ }^{14}$ also examined the effect of reductant type on the energy requirement of reduction, and the effect of packed bed depth, and those results are to be reported separately.

\section{Experimental}

\section{Furnace configuration}

A custom experimental setup was developed to provide uni-directional radiative heating to a sample which was a packed bed of iron ore and coal; the setup included a facility to transport the sample into and out of the heating zone, under an inert atmosphere, with product gas analysis. The essential features of the setup were quantification of radiative heat transfer by measurement of the relevant temperatures, measurement of the overall reduction rate by off-gas analysis, assessment of internal temperature differences within the packedbed sample, and the possibility to halt radiative heat transfer and to cool the sample under argon, for subsequent chemical and microscopical analysis.

As illustrated in Fig. 1, the experimental setup was constructed in a vertical tube furnace, with an alumina working tube. Water cooled brass end caps with rubber O-rings provided gas tight seals to the upper and lower 


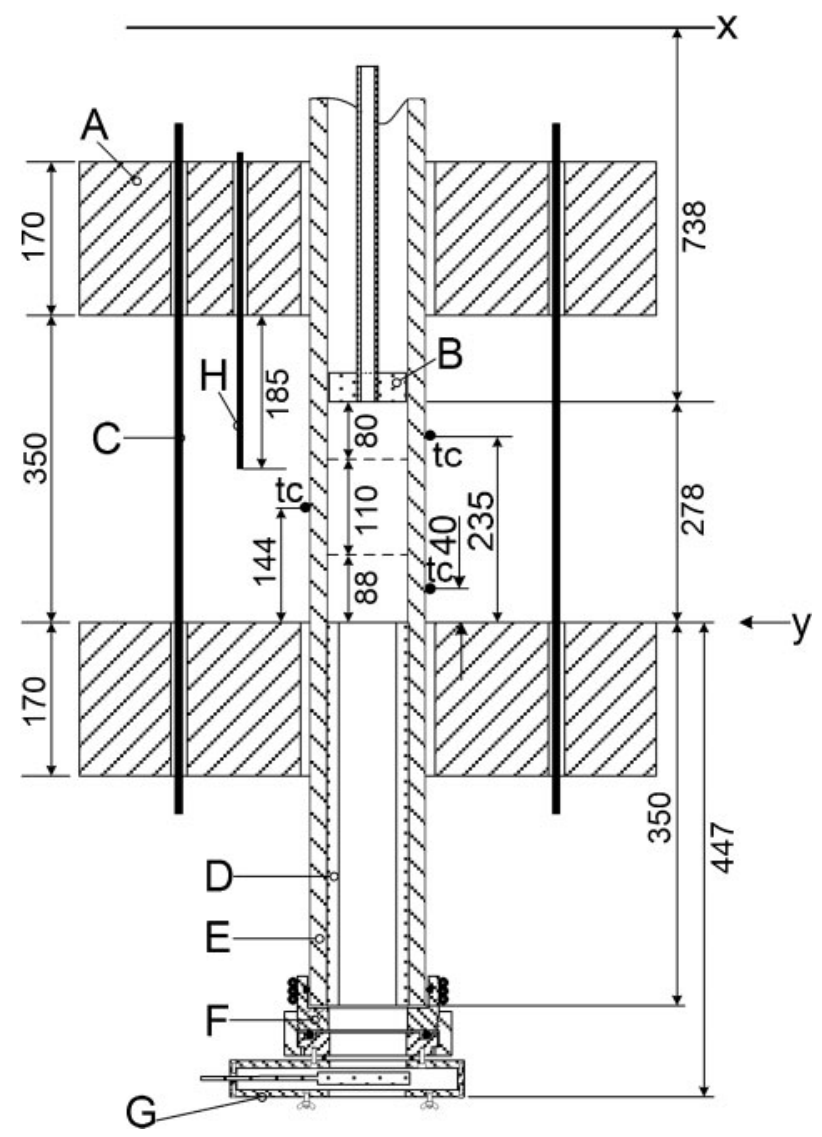

A: refractory lining of furnace; B: upper radiation shield; C: heating element; D: lower radiation shield; E: alumina furnace tube; F: lower end cap; G: slide gate assembly; $\mathrm{H}$ : control thermocouple; tc: location of thermocouples; $\mathrm{x}$ : viewport level; $\mathrm{y}$ : level of top surface of crucible during reaction period

1 Furnace layout: all dimensions are in millimetres

ends of the alumina tube. The upper end cap contained a sight glass for sample surface temperature measurement with an infrared thermometer (pyrometer). An upper radiation shield consisted of a fibreboard disk attached to the end of a mullite tube (Ø20 mm od, Ø15 mm id), held in place at its top by O-rings within the upper end cap. The mullite tube also served as the view hole guide for the pyrometer readings. A lower radiation shield filled the gap between the sample and the alumina working tube, to avoid radial heat transfer to or from the sample. A slide gate assembly was attached to the lower end cap. An aluminium sample lifting tube (not shown in Fig. 1) was in turn attached to the lower part of the slide gate; the sample lifting tube contained a pedestal holder that lifted the sample into the furnace through a piston action. The aluminium pedestal holder functioned as a piston inside the aluminium tube, by sliding on two O-rings seated in circumferential grooves at the upper and lower ends of the cylindrical pedestal holder. The sample was raised into the furnace by letting argon flow into the bottom end of the sample tube, through a control valve set at $50 \mathrm{kPa}$ gauge pressure. A stopper ring at the top of the aluminium tube arrested the aluminium pedestal holder such that the sample surface was level with upper surface of the lower radiation shield (see Fig. 1). To lower the sample back into the sample tube the argon was evacuated from the tube by a rotary vacuum pump. Four K-type

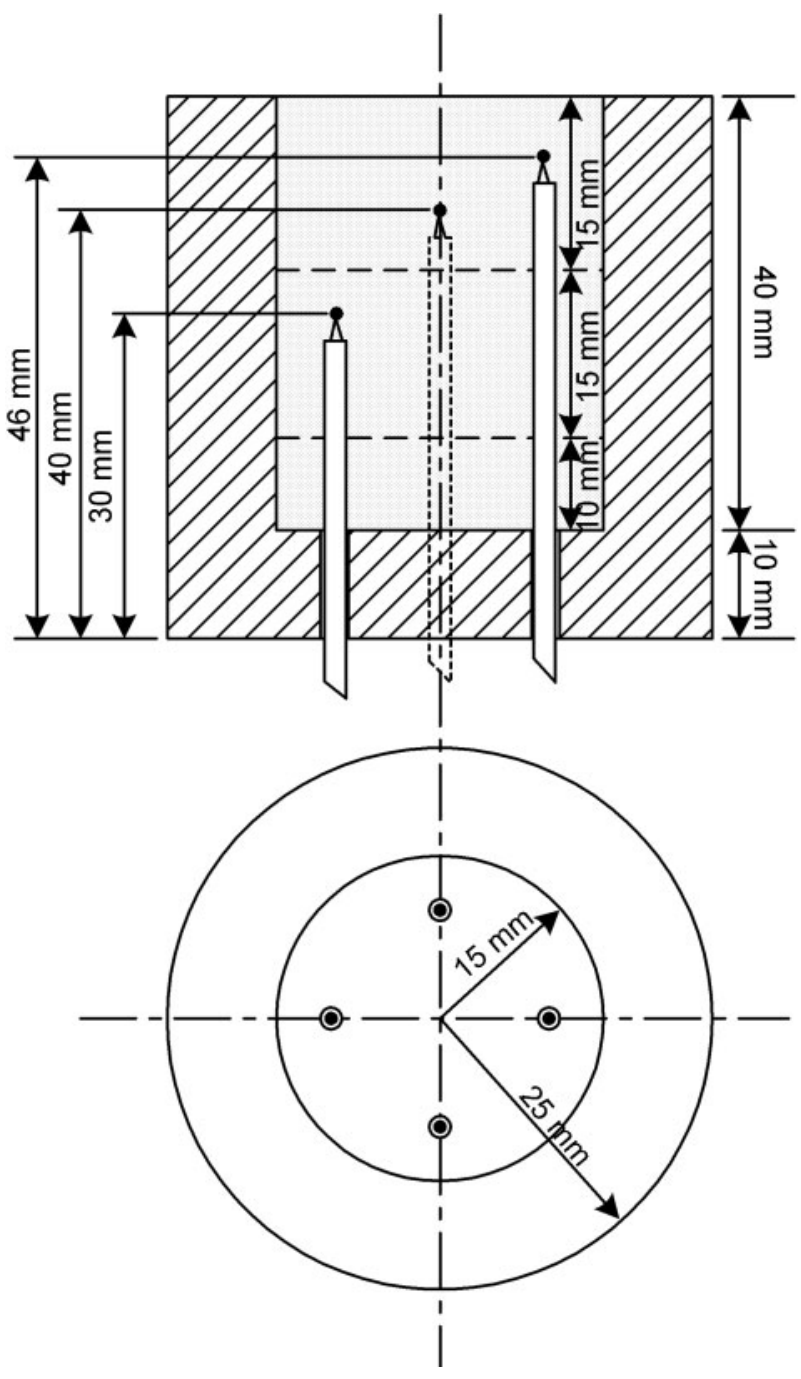

2 Fibreboard crucible, showing positions of thermocouples: broken lines show positions of planes along which sample was separated after reaction

thermocouples passed through the centre of the pedestal. The thermocouple wires were of $0.38 \mathrm{~mm}$ diameter, with twin bore alumina sheaths $(2 \cdot 2 \mathrm{~mm}$ od $)$. The tips of the thermocouples were at different depths within the packed bed sample; see Fig. 2. Temperatures were logged at a rate of $1 \mathrm{~Hz}$.

The packed bed sample was contained in a crucible machined out of low density fibreboard (crucible id $30 \mathrm{~mm}$, od $50 \mathrm{~mm}$ and crucible bottom $10 \mathrm{~mm}$ thick). The crucible was completely filled with the ore-coal mixture.

Argon gas of $99.999 \%$ purity was used as carrier gas; the gas was further purified by passage through anhydrous $\mathrm{CaSO}_{4}$ to remove water, and through an Oxysorb cartridge to remove oxygen, before entry into the furnace. The carrier gas flow rate was measured with a rotameter, and was typically around $35 \mathrm{~N} \mathrm{~cm}^{3} \mathrm{~min}^{-1}$. The product gas off-take lines, $6 \mathrm{~mm}$ od copper tubing, were heated by trace heating to prevent condensation of water from the product gas. The product gas was analysed with a quadrupole mass spectrometer and a chilled mirror hygrometer.

Resistive heating of the furnace was by means of six lanthanum chromite elements, using the standard PID controller and type B control thermocouple (positioned next to the furnace tube, radially close to the hot zone, 
Table 1 Actual (furnace) temperatures and apparent temperatures (measured with pyrometer set to an emissivity of 1.00 ), for different alumina materials

\begin{tabular}{lcc}
\hline & \multicolumn{2}{c}{ Apparent temperature, $\varepsilon=\mathbf{1}$} \\
\cline { 2 - 3 } $\begin{array}{l}\text { Actual } \\
\text { temperature }{ }^{\circ} \mathbf{C}\end{array}$ & $\begin{array}{l}\text { Alumina } \\
\text { powder }\end{array}$ & $\begin{array}{l}\text { Alumina } \\
\text { furnace tube }\end{array}$ \\
\hline 999 & $946 \cdot 3$ & $946 \cdot 0$ \\
1104 & $1032 \cdot 1$ & $1047 \cdot 0$ \\
1208 & $1126 \cdot 8$ & $1146 \cdot 0$ \\
1306 & $1204 \cdot 8$ & $1244 \cdot 8$ \\
\hline
\end{tabular}

and vertically close to the middle of the furnace element heating zone; see Fig. 1). Hot zone temperatures of 1300,1400 and $1500^{\circ} \mathrm{C}$ were used.

\section{Sample surface temperature measurement and radiation calculations}

The sample surface temperature was measured with an infrared pyrometer. The thermal radiation reached the pyrometer through the mullite tube ( $738 \mathrm{~mm}$ long) in the centre of the upper radiation tube, and then through the sight glass (4 mm thick ROBAX glass) in the upper end cap. Accurate temperature measurement required knowledge of the emissivity of the sample surface and the transmissivity of the sight glass, and the radiation network required measured emissivity values of the alumina working tube. The pyrometer measured over the wave length range 0.8 to $1 \cdot 1 \mu \mathrm{m}$; the transmissivity of the sight glass varies from 0.91 to 0.88 over this wavelength range.

The emissivities of samples of the alumina working tube, and alumina powder (used for testing the surface temperature measurement as described below) were measured by heating these materials in a muffle furnace to temperatures of $999,1104,1208$ and $1306^{\circ} \mathrm{C}$ (checked with a hand held type $\mathrm{S}$ thermocouple). Apparent surface temperatures of the samples were measured with the pyrometer (with an emissivity setting of 1) upon briefly opening the muffle furnace door. The Planck blackbody radiation law was used to back calculate the emissivity such that the material sample surface temperature was equal to the furnace temperature. Calculations were performed for both the upper $(1 \cdot 1 \mu \mathrm{m})$ and lower $(0 \cdot 8 \mu \mathrm{m})$ limits of the pyrometer spectral response; the emissivity values calculated for $0.95 \mu \mathrm{m}$ and $1306^{\circ} \mathrm{C}$ furnace temperature were used in further calculations. The temperature measurements are summarised in Table 1, with the calculated emissivities in Table 2. The emissivity of the ore-coal sample surface was assumed to be 0.9 (with sensitivity analysis performed on this, as reported later in this paper).
Table 2 Emissivities calculated from the values in Table 1, for different wavelengths

\begin{tabular}{|c|c|c|c|c|c|c|}
\hline \multirow{3}{*}{$\begin{array}{l}\text { Furnace } \\
\text { temperature, } \\
{ }^{\circ} \text { C }\end{array}$} & \multirow{2}{*}{\multicolumn{3}{|c|}{$\begin{array}{l}\text { Alumina powder } \\
\text { Wavelength, } \mu \mathrm{m}\end{array}$}} & \multirow{2}{*}{\multicolumn{3}{|c|}{$\begin{array}{l}\text { Alumina furnace tube } \\
\text { Wavelength, } \mu \mathrm{m}\end{array}$}} \\
\hline & & & & & & \\
\hline & 0.80 & 0.95 & $1 \cdot 10$ & 0.80 & 0.95 & $1 \cdot 10$ \\
\hline 999 & 0.54 & 0.60 & 0.64 & 0.54 & 0.59 & 0.64 \\
\hline 1104 & 0.49 & 0.55 & 0.59 & 0.57 & 0.62 & 0.66 \\
\hline 1208 & 0.49 & 0.55 & 0.60 & 0.59 & 0.64 & 0.68 \\
\hline 1306 & 0.46 & 0.52 & 0.57 & 0.63 & 0.68 & 0.72 \\
\hline
\end{tabular}

To test the accuracy of the sample surface temperature measurement made with the pyrometer, the actual surface temperature of an inert alumina powder sample was measured with a type $\mathrm{S}$ thermocouple, positioned $5 \mathrm{~mm}$ below the sample surface. The sample was introduced into the furnace, and once the sample temperature stabilised, sample surface temperature measurements were made simultaneously using the type-S thermocouple and the pyrometer (emissivity set at $1 \cdot 00$ ). The measured temperature was then corrected for the alumina powder emissivity of 0.52 , with results given in Table 3: the pyrometer over-reads the sample surface temperature by $6^{\circ} \mathrm{C}$ at $1300^{\circ} \mathrm{C}$ furnace temperature, and under-reads by $14^{\circ} \mathrm{C}$ at $1500^{\circ} \mathrm{C}$ furnace temperature.

The rate of radiative heat transfer to the upper surface of the sample was calculated from the measured sample surface temperature, and temperatures measured along the length of the alumina working tube, with locations as given in Fig. 1, and using type $\mathrm{S}$ thermocouples in contact with the outer surface of the working tube. Each of the temperature readings was taken to represent a separate radiative heating zone, which exchanged radiation with one another and with the sample; see Fig. 3 for the radiation network which was used for the calculations. The procedure as outlined in $\operatorname{Holman}^{15}$ was followed to calculate the radiation view factors and the radiative heat transfer rate.

To test the sensitivity of the radiation network calculation (of heat transfer to the sample surface) to changes in input values, the inputs were varied and the effect on the heat flux to the sample surface noted. Temperatures measured for an ore-graphite mixture reacted at a $1400^{\circ} \mathrm{C}$ furnace temperature were used as the basis for the calculations; the results are given in Table 4. The table illustrates that the sample surface emissivity has the biggest influence on the calculated heat transfer rate, followed by the temperature of heating zone 3 (closest to the sample). The emissivity of the sample is high because of its porous nature; literature values for emissivity of similar samples are $0 \cdot 85$ and $1 \cdot 0 . .^{3,16}$ If the assumed sample

Table 3 Comparison of surface temperature of alumina powder samples, as measured with S-type thermocouple and pyrometer (1300a and $1300 \mathrm{~b}$ are repeat measurements)

\begin{tabular}{|c|c|c|c|c|}
\hline $\begin{array}{l}\text { Furnace } \\
\text { hot zone } \\
\text { temperature, }{ }^{\circ} \mathrm{C}\end{array}$ & $\begin{array}{l}\text { Pyrometer } \\
\text { measurement, } \\
{ }^{\circ} \mathbf{C}(\varepsilon=1 \cdot 00)\end{array}$ & $\begin{array}{l}\text { S-type } \\
\text { thermocouple } \\
\text { measurement, }{ }^{\circ} \mathrm{C}\end{array}$ & $\begin{array}{l}\text { Pyrometer } \\
\text { measurement } \\
\text { corrected for } \varepsilon=0.52,{ }^{\circ} \mathrm{C}\end{array}$ & $\Delta T^{*}$ \\
\hline $1300 a$ & 1076 & 1172 & 1177 & -6 \\
\hline $1300 b$ & 1082 & 1178 & 1184 & -6 \\
\hline 1400 & 1172 & 1290 & 1288 & 2 \\
\hline 1500 & 1250 & 1394 & 1380 & 14 \\
\hline
\end{tabular}

*Error, calculated as: (S-type thermocouple measurement)-(corrected pyrometer measurement). 


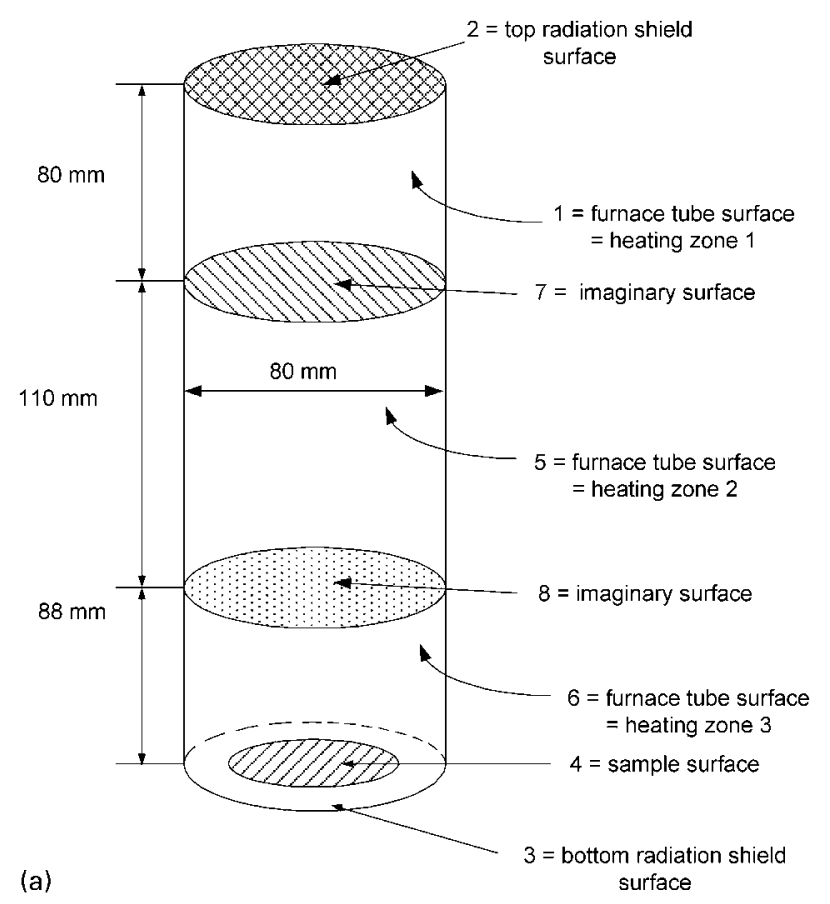

(a)

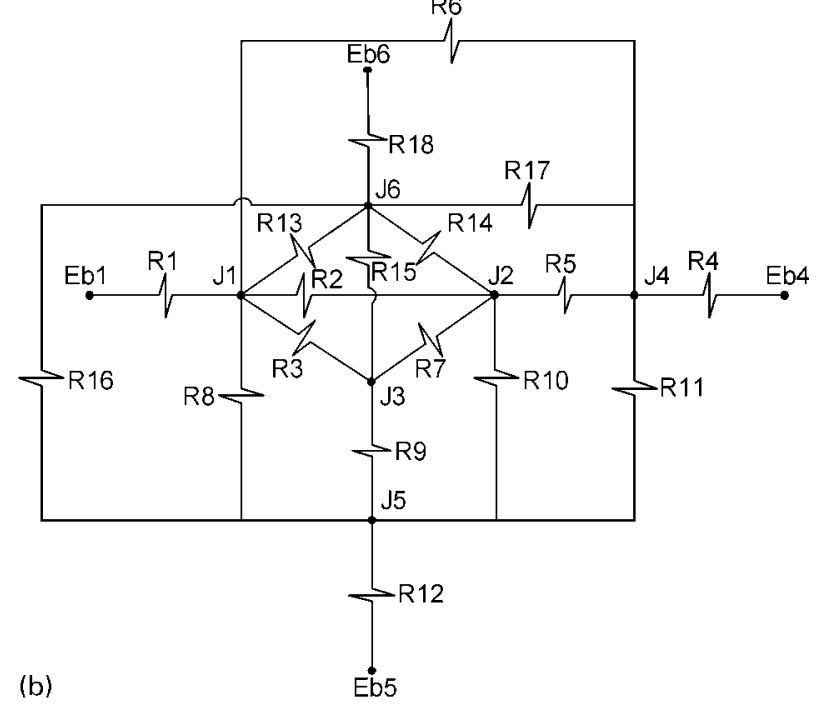

a location and identification of isothermal radiating surfaces; $b$ electrical analogue of radiation network

3 Radiation network used to calculate radiative heat transfer to the sample surface

emissivity $(0 \cdot 90)$ is taken to be correct, the estimated maximum error in the heat transfer calculation due to the other factors is $\pm 19 \mathrm{~kW} \mathrm{~m}^{-2}$.

\section{Sample analysis}

After the reaction period the sample was lowered to cease radiative heating. Once cooled, the sample was separated axially into three separate portions, to allow vertical variation in the extent of reaction to be determined by analysis. Because the sample was not agglomerated before reaction, a special steel cutting tool was constructed to effect the separation; the cutter, which is illustrated in Fig. 4, could shear through thermocouple sheaths where these were sintered to the sample. Consistent sample separation was important to the mass and energy balance calculations, and reproducibility of the cutting action was hence tested using 10 samples of silica sand in fibre board crucibles. The fractions of the total material in the three sections (with $95 \%$ confidence intervals) were $46 \pm 1 \cdot 0 \%$ (top), $33 \pm 0 \cdot 3 \%$ (middle) and $21 \pm 0 \cdot 9 \%$ (bottom). For reacted samples, some contraction affected the relative amounts of material in the three sections; the maximum vertical contraction was $2 \mathrm{~mm}$. A possible alternative to this sectioning method would have been to impregnate the entire sample with resin, to allow examination of polished sections. This was not used because resin mounting would have precluded bulk chemical analysis for carbon and for iron valency.

An important assumption in the analysis was that the degree of reaction varied along the sample axis only, because of the one-dimensional (vertical) heat transfer. This assumption was checked by optical metallography of polished cross-sections through reacted samples (immobilised in epoxy resin after reaction). This confirmed the absence of radial variation in the extent of reaction (in contrast with very strong axial differences).

Chemical analysis of the split samples included inductively coupled plasma (ICP) for elemental analyses, carbon by LECO method, and valence of iron ('forms of iron') by wet chemical analysis. Based on the iron analyses, the percentage reduction was calculated relative to $\mathrm{Fe}_{2} \mathrm{O}_{3}$.

\section{Mixtures for calibration runs}

Well defined samples, with respect to their chemical composition and size distribution, were used for 'calibration runs', in which the calculated total radiative heat transfer was compared with the energy change in the sample (from a mass and energy balance), and the calculated change in sample carbon content (determined from the off-gas analysis) was compared with the analysed carbon content. For these runs, the reagents were pre-reduced South African Northern Cape iron ore (containing mainly wüstite, some magnetite, and gangue; see Table 5 for chemical analysis) and graphite $(98 \cdot 7 \% \mathrm{C})$, in the size range $-850+425 \mu \mathrm{m}$. From the analysis in Table 5 , the percentage reduction of the starting mixture was $25 \cdot 7 \%$. The ore-graphite sample mass was typically $44 \mathrm{~g}$ and the mixture contained $14 \cdot 6 \%$ graphite by mass. The graphite and ore portions were weighed into a small glass container and thoroughly hand mixed with a spatula. The mixture was tipped into a short stemmed funnel while this funnel was seated on the bottom of the crucible. The funnel was then lifted as quickly as possible from the crucible to reduce the material flow period, and to avoid segregation of the feed.

\section{Results, analysis and discussion}

Typical thermal history and off-gas composition

Three calibration experiments were performed in duplicate, at furnace hot zone set point temperatures of 1300 , 1400 and $1500^{\circ} \mathrm{C}$. As an example of the results obtained, Fig. $5 a$ and $b$ shows the logged temperatures and the product gas analyses for a sample reacted at furnace hot zone set point temperature of $1400^{\circ} \mathrm{C}$ for $15 \mathrm{~min}$. Rapid heating of the sample surface is evident; introduction of the sample caused little disturbance to the temperature of the working tube. The substantial temperature differences within the sample, and between the sample surface and the working tube, show that both conduction within the sample and radiation to the sample 


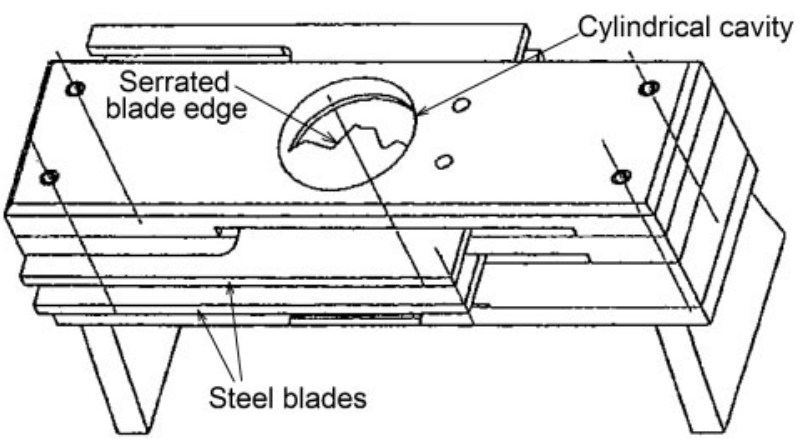

4 Sample cutter, used to section sample within crucible after reaction: crucible fitted into cylindrical cavity; four steel blades with serrated edges cut sample into three sections (at levels indicated with broken lines in Fig. 2)

surface were limiting. (The anomalous behaviour of the thermocouple placed $4 \mathrm{~mm}$ below the initial sample surface is discussed below.) The off-gas can be seen to be mainly $\mathrm{CO}$ and $\mathrm{CO}_{2}$, with some water vapour released early in the reaction period (from drying of the sample), and some hydrogen (from reaction of water vapour with the carbon). The $\mathrm{CO} / \mathrm{CO}_{2}$ ratio of the off-gas changes over the reaction period, and can be seen to lie between the compositions for equilibrium with solid carbon (Boudouard reaction; equilibrium ratio $\mathrm{CO} /$ $\mathrm{CO}_{2}=5 \times 10^{3}$ at $1100^{\circ} \mathrm{C}$ surface temperature, for $\left.p_{\mathrm{CO}}+p_{\mathrm{CO} 2}=0.08 \mathrm{~atm}\right)$ and for equilibrium with $\mathrm{Fe}$ and wüstite (equilibrium ratio $\mathrm{CO} / \mathrm{CO}_{2}=3 \cdot 0$ at $1100^{\circ} \mathrm{C}$ ). Hence the reaction kinetics in this test involves a combination of heat transfer control and mixed chemical reaction control; this complex situation is characteristic of the conditions in the process which this configuration was designed to simulate. Figure 5 also demonstrates that the sample temperature decreased rapidly when the sample was lowered, causing the reactions to cease (as seen from the $\mathrm{CO}$ and $\mathrm{CO}_{2}$ contents of the off-gas returning to zero).

The conditions at the end of the reaction period, for the six samples and the subsamples obtained from these with the cutter, are summarised in Table 6 . The table shows that the degree of reduction in all the 'middle' and 'bottom'
Table 5 Chemical composition of prereduced ore (mass percentages)

\begin{tabular}{ll}
\hline $\mathrm{Fe}$ (total) & $71 \cdot 1$ \\
$\mathrm{FeO}$ & $68 \cdot 1$ \\
$\mathrm{Fe}_{2} \mathrm{O}_{3}$ & $25 \cdot 0$ \\
$\mathrm{Fe}^{\mathrm{O}}$ & $0 \cdot 64$ \\
$\mathrm{SiO}_{2}$ & $3 \cdot 84$ \\
$\mathrm{Al}_{2} \mathrm{O}_{3}$ & $1 \cdot 81$ \\
$\mathrm{~K}_{2} \mathrm{O}$ & 0.23 \\
$\mathrm{CaO}$ & $0 \cdot 10$ \\
$\mathrm{TiO}$ & 0.08 \\
$\mathrm{P}$ & 0.05 \\
$\mathrm{MgO}$ & 0.04 \\
$\mathrm{MnO}$ & 0.04
\end{tabular}

samples was unchanged from that of the starting material: during $15 \mathrm{~min}$ of heating only the top portion of the sample showed a significant increase in reduction. The sample temperatures are lower and the degree of reduction smaller for the tests done at $1500^{\circ} \mathrm{C}$, since at this temperature a shorter reaction time of $4.5 \mathrm{~min}$ was used because of the onset of melting at the sample surface.

\section{Mass and energy balance}

Given the central and possibly rate determining role of heat transfer, it was important to complete mass and energy balances (on the reacting sample) which were as accurate as possible, for comparison with the calculated heat transfer rate. Three separate mass and energy balances were completed for each of the subsamples ('nodes') in the larger sample, for each test. The required assumptions are listed below:

(i) the oxygen from reduction left as $\mathrm{CO}$ or $\mathrm{CO}_{2}$. This assumption is based on the zero volatile content of the graphite reductant, and the presence of little $\mathrm{H}_{2}$ and $\mathrm{H}_{2} \mathrm{O}$ in the product gas

(ii) since reduction occurred only in the top node, the $\mathrm{CO}$ and $\mathrm{CO}_{2}$ in the product gas were generated from the top node only, and were taken to exit the sample at the top node temperature

(iii) the total water measured in the product gas was taken as part of the input sample, and was released with the rest of the product gas from the sample at the top node temperature

Table 4 Sensitivity of calculated radiative heat transfer rate to input values (numbers refer to radiation network shown in Fig. 3)

\begin{tabular}{|c|c|c|c|c|}
\hline Parameter & $\begin{array}{l}\text { Parameter } \\
\text { value } \\
\text { change }\end{array}$ & $\begin{array}{l}\text { Parameter } \\
\text { basis } \\
\text { value }\end{array}$ & $\begin{array}{l}\text { Calculated } \\
\text { heat flux, } \\
\mathrm{kW} \mathrm{m}^{-2}\end{array}$ & $\begin{array}{l}\text { Difference } \\
\text { from } \\
\text { basis }\end{array}$ \\
\hline Basis & - & - & -167 & 0 \\
\hline Measured sample surface temperature (surface 4) & $+15^{\circ} \mathrm{C}$ & $1093^{\circ} \mathrm{C}$ & -159 & -8 \\
\hline Measured sample surface temperature (surface 4) & $-15^{\circ} \mathrm{C}$ & $1093^{\circ} \mathrm{C}$ & -176 & 9 \\
\hline Heating zone no. 1 temperature (surface 1 ) & $+15^{\circ} \mathrm{C}$ & $1409^{\circ} \mathrm{C}$ & -168 & +1 \\
\hline Heating zone no. 1 temperature (surface 1) & $-15^{\circ} \mathrm{C}$ & $1409^{\circ} \mathrm{C}$ & -167 & 0 \\
\hline Heating zone no. 2 temperature (surface 5) & $+15^{\circ} \mathrm{C}$ & $1405^{\circ} \mathrm{C}$ & -170 & +3 \\
\hline Heating zone no. 2 temperature (surface 5) & $-15^{\circ} \mathrm{C}$ & $1405^{\circ} \mathrm{C}$ & -165 & -2 \\
\hline Heating zone no. 3 temperature (surface 6) & $+15^{\circ} \mathrm{C}$ & $1346^{\circ} \mathrm{C}$ & -177 & +10 \\
\hline Heating zone no. 3 temperature (surface 6) & $-15^{\circ} \mathrm{C}$ & $1346^{\circ} \mathrm{C}$ & -158 & -9 \\
\hline Furnace tube emissivity: $\varepsilon_{1}, \varepsilon_{5}, \varepsilon_{6}$ & $+0 \cdot 10$ & 0.68 & -167 & 0 \\
\hline Furnace tube emissivity: $\varepsilon_{1}, \varepsilon_{5}, \varepsilon_{6}$ & $-0 \cdot 10$ & $0 \cdot 68$ & -168 & +1 \\
\hline Sample surface emissivity $\varepsilon_{4}$ & +0.09 & 0.90 & -191 & +24 \\
\hline Sample surface emissivity $\varepsilon_{4}$ & $-0 \cdot 10$ & 0.90 & -141 & -26 \\
\hline Bottom radiation shield emissivity $\varepsilon_{3}$ & $+0 \cdot 10$ & 0.53 & -167 & 0 \\
\hline Bottom radiation shield emissivity $\varepsilon_{3}$ & $-0 \cdot 10$ & 0.53 & -167 & 0 \\
\hline Top radiation shield emissivity $\varepsilon_{2}$ & $+0 \cdot 10$ & 0.54 & -167 & 0 \\
\hline Top radiation shield emissivity $\varepsilon_{2}$ & $-0 \cdot 10$ & 0.54 & -167 & 0 \\
\hline
\end{tabular}



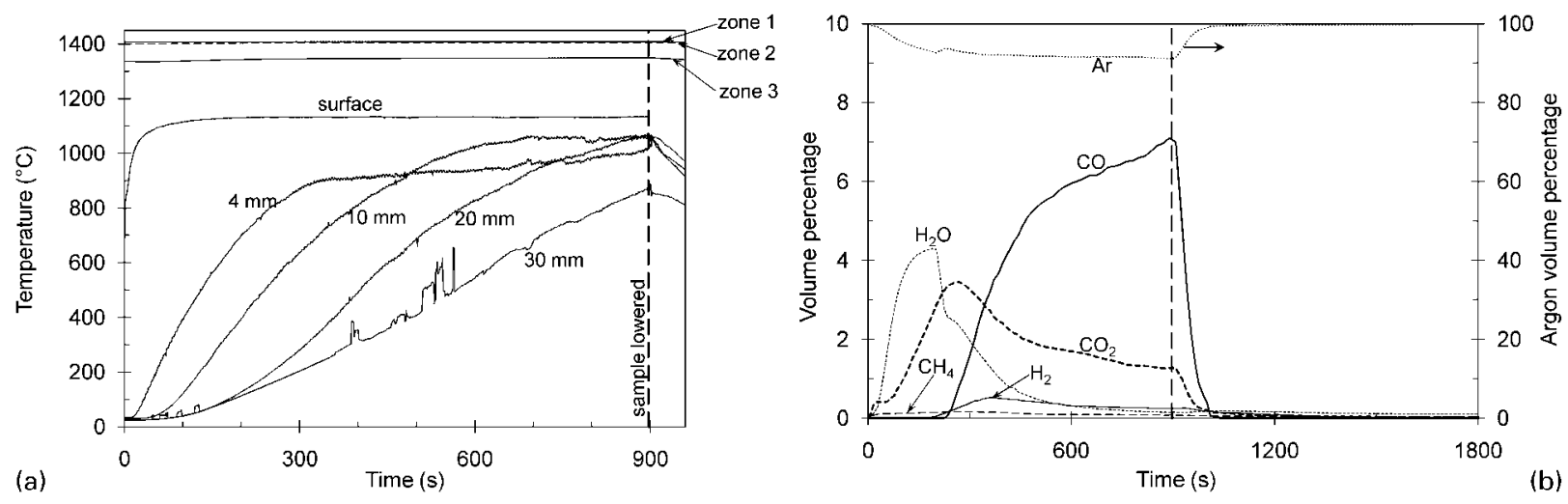

a measured temperatures; zones 1-3 are working tube temperatures, 'surface' is sample surface temperature as measured by pyrometer, and curves labelled ' $4 \mathrm{~mm}$ ', ' $10 \mathrm{~mm}$ ', ' $20 \mathrm{~mm}$ ' and ' $30 \mathrm{~mm}$ ' give measured temperatures at these distances from original sample surface; $b$ off-gas analysis; argon is plotted against right hand axis, and all other species against left hand axis

5 Temperature measurements and off-gas analysis from reaction of sample at $1400^{\circ} \mathrm{C}$ furnace temperature: at time zero sample was raised to reaction level, and after $900 \mathrm{~s}$ (indicated with broken line) it was lowered

(iv) each node was taken to be uniform in temperature. The temperatures measured with the four thermocouples were used to estimate the node temperatures. The top node was taken to be at the temperature measured $10 \mathrm{~mm}$ from the sample surface; the middle node was at the temperature $20 \mathrm{~mm}$ from the sample surface; and the bottom node was at the temperature $30 \mathrm{~mm}$ from the sample surface. As Fig. $5 a$ illustrates the thermocouple $4 \mathrm{~mm}$ from the sample surface often reached a plateau temperature which was lower than at $10 \mathrm{~mm}$ and sometimes even $20 \mathrm{~mm}$ from the sample surface. This anomalous behaviour is likely caused by loss of thermal contact between the thermocouple and the solids of the packed bed, as the bed shrinks locally and macroscopically during reduction. However, in the case of the shorter $1500^{\circ} \mathrm{C}$ tests the temperature $10 \mathrm{~mm}$ below the sample surface was much lower than that measured $4 \mathrm{~mm}$ from the sample surface, and the latter as taken was the top node temperature for these two tests only.

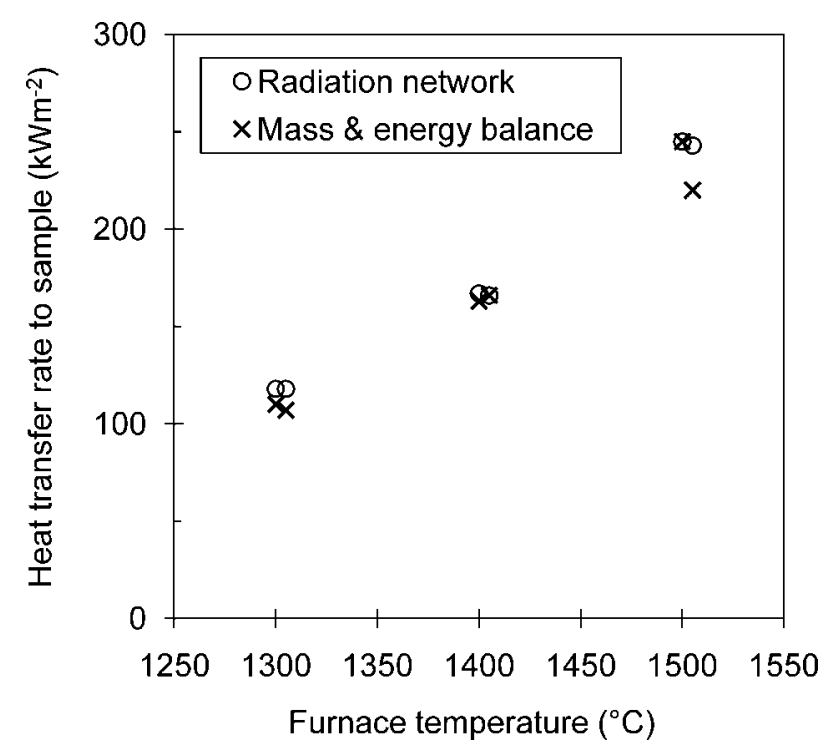

6 Average heat transfer rate to sample surface over reaction period, as calculated from radiation network and from mass and energy balance

Table 6 Summary of end point conditions (temperatures and analyses), just before sample was lowered

\begin{tabular}{|c|c|c|c|c|c|c|c|}
\hline $\begin{array}{l}\text { Furnace } \\
\text { temperature, }{ }^{\circ} \mathrm{C}\end{array}$ & Sample no. & Subsample & $\begin{array}{l}\text { Final } \\
\text { temperature, }{ }^{\circ} \mathrm{C}\end{array}$ & $\begin{array}{l}\text { Mixture } \\
\text { mass*, g }\end{array}$ & $\begin{array}{l}\text { Fibre board } \\
\text { mass, } g\end{array}$ & $\% C^{*}$ & $\%$ reduction \\
\hline \multirow[t]{3}{*}{1300} & $1300 \mathrm{~A}$ & Top & 1071 & $15 \cdot 4$ & 14.5 & 12.9 & $45 \cdot 4$ \\
\hline & & Middle & 1030 & $15 \cdot 4$ & $4 \cdot 2$ & $13 \cdot 2$ & $25 \cdot 5$ \\
\hline & & Bottom & 974 & $10 \cdot 7$ & $12 \cdot 9$ & $15 \cdot 1$ & 23.9 \\
\hline \multirow[t]{3}{*}{1300} & $1300 \mathrm{~B}$ & Top & 1051 & $18 \cdot 2$ & $11 \cdot 2$ & $12 \cdot 4$ & $38 \cdot 8$ \\
\hline & & Middle & 1027 & $14 \cdot 6$ & 6.9 & $12 \cdot 7$ & $25 \cdot 2$ \\
\hline & & Bottom & 954 & $8 \cdot 6$ & $12 \cdot 9$ & $18 \cdot 7$ & $24 \cdot 5$ \\
\hline \multirow[t]{3}{*}{1400} & $1400 \mathrm{C}$ & Top & 1054 & $16 \cdot 0$ & $11 \cdot 7$ & $10 \cdot 5$ & $46 \cdot 6$ \\
\hline & & Middle & 1071 & $15 \cdot 1$ & $7 \cdot 3$ & $13 \cdot 5$ & $25 \cdot 6$ \\
\hline & & Bottom & 874 & $9 \cdot 5$ & $13 \cdot 4$ & $18 \cdot 0$ & $24 \cdot 7$ \\
\hline \multirow[t]{3}{*}{1400} & $1400 D$ & Top & 1077 & $15 \cdot 1$ & $12 \cdot 1$ & $12 \cdot 2$ & $54 \cdot 8$ \\
\hline & & Middle & 1014 & $14 \cdot 8$ & $7 \cdot 0$ & $11 \cdot 1$ & $26 \cdot 1$ \\
\hline & & Bottom & 922 & $9 \cdot 7$ & $13 \cdot 2$ & $16 \cdot 2$ & $25 \cdot 2$ \\
\hline \multirow[t]{3}{*}{1500} & $1500 E$ & Top & 909 & $18 \cdot 7$ & $11 \cdot 8$ & $16 \cdot 8$ & $31 \cdot 4$ \\
\hline & & Middle & 268 & $15 \cdot 4$ & 6.9 & $12 \cdot 2$ & $21 \cdot 2$ \\
\hline & & Bottom & 206 & $9 \cdot 1$ & $13 \cdot 6$ & $13 \cdot 9$ & $23 \cdot 3$ \\
\hline \multirow[t]{3}{*}{1500} & $1500 F$ & Top & 981 & $11 \cdot 5$ & $5 \cdot 8$ & $14 \cdot 6$ & $36 \cdot 5$ \\
\hline & & Middle & 316 & 14.5 & $7 \cdot 7$ & $14 \cdot 3$ & $23 \cdot 0$ \\
\hline & & Bottom & 234 & $16 \cdot 9$ & $17 \cdot 3$ & $13 \cdot 6$ & $22 \cdot 9$ \\
\hline
\end{tabular}

*Excluding crucible material (fibreboard). 


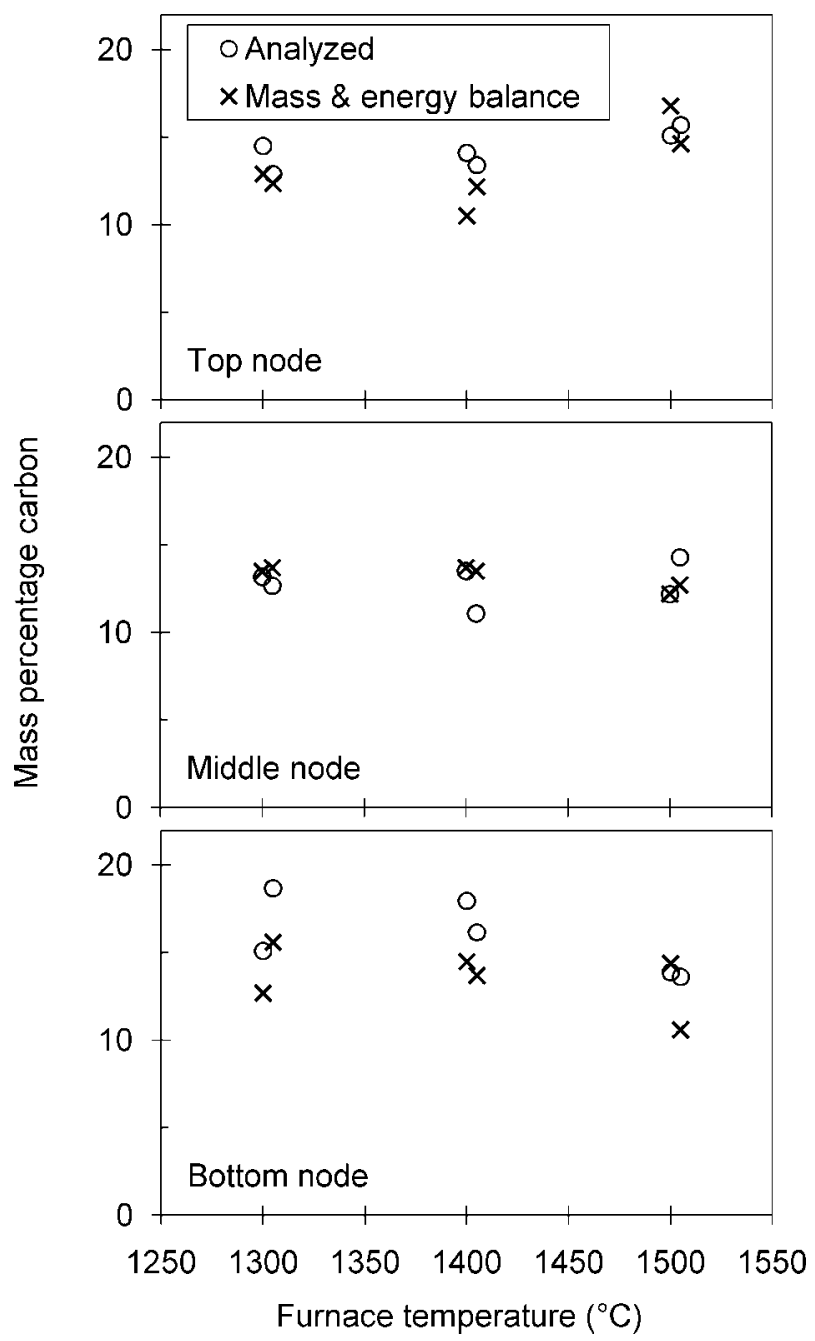

7 Comparison of LECO analysis of carbon content with carbon content predicted by mass and energy balance, for different nodes in sample after reaction

(v) the mass of crucible material in each subsample was found from mass measurements on the sectioned samples. The crucible material (composition $65 \% \mathrm{Al}_{2} \mathrm{O}_{3}, 35 \% \mathrm{SiO}_{2}$ ) was taken to be mullite in the energy balance

(vi) the argon carrier gas which flows past the crucible and sample was taken to be heated to the top node temperature.

Since the product gas composition and temperature changed over the reaction period, the mass and energy balance was calculated for each measurement time increment, and then accumulated to find the total heat transferred to the sample; this total is compared in Fig. 6 with that calculated from the radiation network. It is seen that, for the experiments at 1300 and $1400^{\circ} \mathrm{C}$ furnace temperature, the two sets of calculations correspond well. Only in one case, experiment $1500 \mathrm{~F}$ for a $1500^{\circ} \mathrm{C}$ furnace temperature, is there a substantial difference between the results, of some $22 \%$. At the short reaction time, high radiative flux and low degrees of reduction for this experiment, the assumption of uniform node temperatures is likely to affect the results, and the effect of errors in temperature measurement is magnified. Overall the conclusion is that the radiation network gives an accurate measure of the rate of heat transfer to the sample, and this method was used to find the heat transferred in subsequent runs with more complex samples (containing ore which was not prereduced, and coal as reductant). ${ }^{14}$

The carbon content as predicted from the mass balance is compared with the analysed values, in Fig. 7. Because of the generally low degrees of reaction, this comparison mainly tests the accuracy of sample splitting and carbon analysis (especially for the lower two sections of each sample). The figure shows that the calculated and analysed carbon contents differ by a maximum of $3 \%$. It is hence concluded that the mechanical device split the sample accurately.

\section{Conclusion}

The experimental setup is appropriate for quantifying radiative heat transfer to ore-coal samples reacted nonisothermally with one-dimensional heating. The sample cutter allows for the repeatable division of the reacted sample into three node portions for further chemical analysis. The experimental conditions led to a combination of radiative and conductive control of heat transfer into the sample.

\section{References}

1. P. C. Pistorius: Scand. J. Metall., 2005, 34, 122-130

2. C. E. Seaton, J. S. Foster and J. Velasco: Trans. Iron Steel Inst. Jpn, 1983, 23, 490-496.

3. V. Venkateswaran and J. K. Brimacombe: Metall. Trans. B, 1977, 8B, 387-398

4. B. C. Cunningham and J. G. Stephenson: in 'Direct reduced iron technology and economics of production and use', (ed. R. Stephenson et al.), 67; 1980, Warrendale, PA, The Iron \& Steel Society of AIME.

5. O. M. Fortini and R. J. Fruehan: Metall. Mater. Trans. B, 2005, 36B, 709-717.

6. S. Sun and W.-K. Lu: ISIJ Int., 1999, 39, 123-129.

7. T. Coetsee, P. C. Pistorius and E. E. de Villiers: Miner. Eng., 2002, 15, 919-929.

8. K. E. Joyner: Revue de Métallurgie, Cahiers d'Informations Techniques, 2000, 97, 461-469.

9. W. Schnabel, D. Schlebusch and G. Elsenheimer: ISS Ironmaking Conf. Proc., 1983, 42, 163-170.

10. W.-K. Lu and D. Huang: US patent 6257879, 2001.

11. L. J. Fourie: US patent 5411570, 1995.

12. L. J. Fourie: US patent 6146437, 2000

13. L. J. Fourie and J. P. de Villiers: US patent 6537342, 2003.

14. T. Coetsee: 'Non-isothermal reaction of iron ore-coal mixtures', PhD thesis, University of Pretoria, Pretoria, South Africa, 2007.

15. J. P. Holman: 'Heat transfer', 8th edn, 394 479; 1992, New York, NY, McGraw-Hill.

16. S. Sun and W.-K. Lu: ISIJ Int., 1999, 39, 130-138. 